\title{
DETERMINANTES DA GOVERNANÇA ELETRÔNICA DOS ESTADOS BRASILEIROS SOB A ÓTICA DA TEORIA DA ESCOLHA PÚBLICA
} ELETRONIC GOVERNANCE DETERMINANTS OF THE BRAZILIAN STATES UNDER THE OPTICS OF THE PUBLIC CHOICE THEORY

\author{
JULIANO FRANCISCO BALDISSERA ${ }^{1}$ \\ NICOLE REGINA SOUZA ROVARI ${ }^{2}$ \\ GILMAR RIBEIRO MELLO ${ }^{3}$ \\ CLÓVIS FIIRST ${ }^{4}$
}

RESUMO: A governança eletrônica aparece como uma tendência emergente para reinventar o funcionamento do governo, especialmente na oferta de serviços públicos e da participação cidadã na gestão, de maneira online. A governança eletrônica exige novas posturas dos gestores, é fundamental observar a relação da Teoria da Escolha Pública com as variáveis que afetam os mecanismos da boa governança. Nesse sentido, essa pesquisa buscou analisar a influência dos indicadores socioeconômicos, contábeis e de transparência na governança eletrônica dos estados em 2011 a 2015. Este estudo adotou uma abordagem quantitativa, utilizando a técnica estatística de regressão linear múltipla. Essa pesquisa permitiu concluir que existe influência negativa entre as variáveis contábeis e os mecanismos de governança eletrônica dos estados brasileiros, além de uma relação positiva entre estes mecanismos de governança e as características socioeconômicas e de transparência dos estados brasileiros. Foi possível analisar os resultados sob a ótica da Teoria da Escolha Pública, em que se permitiu observar nos casos em que os estados apresentam abordagens de gestão não tão interessantes à sociedade, como utilizar recursos por meio de operações de crédito, dependência maior de recursos de terceiros e existência de muitos gastos com pessoal, o índice de governança eletrônica se mostrou menor. Além disso, a associação positiva com a transparência pública é explicada pelo fato de que esta é um mecanismo que limita a maximização do interesse particular do gestor.

Palavras-chave: Governança Eletrônica; Transparência; Teoria da Escolha Pública; Indicadores Contábeis; Variáveis Socioeconômicas.

ABSTRACT: Electronic governance appears as an emergent trend to reinvent the functioning of government, especially in the provision of public services and citizen participation in management, on-line. Electronic governance requires new positions of managers, it is fundamental to observe the relationship of Public Choice Theory as variables that affect the mechanisms of good governance. In this sense, this research sought to analyze the influence of socioeconomic, accounting and transparency indicators in the electronic governance of Brazilian states in 2011 to 2015. This study adopted a quantitative approach, using the statistical technique of multiple linear regression. This research allowed to conclude the

\footnotetext{
Data de submissão: 14/09/2017 Data de aceite: 17/06/2018 Data de publicação: 08/08/2018

1 Universidade Estadual do Oeste do Paraná (Unioeste)

${ }^{2}$ Universidade Estadual do Oeste do Paraná (Unioeste)

${ }^{3}$ Universidade Estadual do Oeste do Paraná (Unioeste)

${ }^{4}$ Universidade Regional de Blumenau (FURB)
} 
existence of a negative influence between accounting variables and systems of electronic governance of Brazilian states, as well as a positive relationship between these mechanisms of governance and the socioeconomic and transparency characteristics of the Brazilian states. It was possible to analyze the results from the point of view of the Public Choice Theory, in which it was possible to observe cases where states present management approaches that are not so interesting to society, such as using resources through credit operations, And the existence of many personnel expenses, the e-governance index was lower, which corroborates with the assumptions of this theory. Moreover, the positive association with public transparency is explained by the fact that this is a mechanism that limits the maximization of the manager's particular interest.

Keywords: Eletronic Governance; Transparency; Public Choice Theory; Accounting Indicators; Socioeconomic variables. 


\section{INTRODUÇÃO}

Os cidadãos estão se tornando mais exigentes com a gestão das organizações públicas e da própria transparência dos atos administrativos destas entidades, esse é um reflexo das mudanças sociais, econômicas e políticas em âmbito mundial e também brasileiro. Diante deste novo contexto, as entidades públicas e privadas passaram a ser obrigadas a adotar novos e inovadores modelos de gestão, assim como novos instrumentos e formas de administração (SOARES JÚNIOR; SANTOS, 2007).

Acompanhando esse movimento, a gestão das organizações tem sofrido diversas reformas no cenário brasileiro, principalmente, a partir de diversos mecanismos legais, como a Lei Complementar (LC) no 101/200 e a LC no 131/2009, além da Lei de Acesso à Informação (Lei no 12.527/2011), que vieram para regulamentar, especialmente, a questão da informação como pública, e intensificar o aspecto da participação dos cidadãos na gestão pública.

Tais exigências legais destes instrumentos normativos fizeram surgir uma necessidade de aprimorar a relação entre a entidade pública e a sociedade, a informação ganhou ainda mais notoriedade. A gestão de conhecimento e a informação são constantemente aprimoradas pela evolução dos sistemas de informação por meio de tecnologias, como a internet e outras tecnologias de comunicação. Governos de diferentes nações estão buscando aproveitar potencialidades oferecidas pelas tecnologias de informação para criar novas dimensões de progresso econômico e social (OKOT-UMA, 2001; POTNIS, 2010).

Isto posto, os portais eletrônicos se prestam ao fornecimento de serviços públicos à sociedade de forma mais transparente e capilar possível, sobretudo pelo volume de recursos e pela gama de serviços extremamente diversificados para públicos diversos, em relação a classes econômicas e culturas distintas. Páginas da internet ou websites possuem a capacidade de fornecer o acesso relativamente seguro, com rapidez e baixo custo, semelhantes às grandes corporações que adotam padrões de governança modernas (ARAÚJO; LAIA, 2004; BHUIYAN, 2011; LAMENHA; LAMENHA, 2015).

Neste escopo, com o advento das tecnologias de informação e comunicação (TICs), a governança eletrônica aparece como uma tendência emergente para reinventar o funcionamento do governo, especialmente na oferta de serviços públicos e da participação cidadã na gestão, de maneira online. Assim, o termo governança eletrônica possui foco no uso de novas TICs aplicadas a um amplo arco das funções do governo e, em especial, deste para a sociedade e para a promoção das práticas da boa governança (MELLO, 2009).

A governança eletrônica reflete o cenário cada vez mais desenvolvido e complexo, que exige novas ações e estilos de liderança, alternativas de debater e decidir estratégias, novas formas de acesso aos serviços, novas transações de negócios, novas formas de acesso à educação, novas maneiras de ouvir a comunidade e, também, novas formas de organização e prestação de informações (OKOT-UMA, 2001; POTNIS, 2010; JANOWSKI; PARDO; DAVIES, 2012).

Aliado a essas discussões, é possível perceber que a governança eletrônica se insere na discussão da Teoria da Escolha Pública, a qual busca oferecer uma compreensão das interações institucionais complexas que ocorrem do setor público (BUCHANAN, 1984). A partir da consideração do homem como um maximizador egoísta, racional e de utilidade, espera-se que os gestores públicos atuem considerando suas preferências individuais (MUELLER, 1976). Assim, dada a necessidade de pensar em regras, procedimentos e 
instituições para evitar os abusos de poder e outras tentações políticas (PEREIRA, 1997), surge a governança eletrônica nesse contexto.

Alguns estudos têm buscado observar os aspectos da governança eletrônica que explicam sua utilização, alguns associam a fatores socioeconômicos como Huther e Shah (1999), Jardim (2004), Kaufmann et al. (2005), Evangelista et al. (2015), Moura et al. (2015), outros já visam analisar tão somente os indicadores contábeis no setor público e possíveis relações, mas não especificamente com a governança, como Santos e Alves (2007), Gusmão, Júnior e Raifur (2008), Macedo e Corbari (2009) e Ribeiro et al. (2012) e, por fim, outros fazem análise dos aspectos que envolvem a transparência dos entes públicos (CRUZ et al., 2012; ANGÉLICO, 2012; BRAGA et al., 2014; NEVES; DINIZ; MARTINS, 2015).

A justificativa dessa pesquisa é pelo fato de que, apesar de a governança eletrônica já ter explicações a partir dos aspectos socioeconômicos, as características contábeis e de transparência não foram analisadas nesse enfoque; é necessário, portanto, apresentar a definição e estruturação destes mecanismos, bem como identificar seus benefícios e demonstrar formas de implantação e evidenciação da governança eletrônica (MELLO, 2009).

Considerando os estudos anteriores e os pressupostos teóricos da Escolha Pública, propõe-se a seguinte questão de pesquisa: qual a influência dos indicadores socioeconômicos, contábeis e de transparência na governança eletrônica dos Estados Brasileiros? Para responder ao problema de pesquisa, tem-se como objetivo deste estudo analisar a influência dos indicadores socioeconômicos, contábeis e de transparência na governança eletrônica dos Estados Brasileiros, no período de 2011 a 2015.

Este estudo está delimitado a observação dos Estados Brasileiros, verificando o Índice de Governança Eletrônica dos Estados Brasileiros (IGEB), já calculado em estudos anteriores, bem como os índices socioeconômicos, contábeis e de transparência, compreendidos no período de 2011 a 2015.

Além desta seção de introdução, este trabalho também apresentará nas seções seguintes o referencial teórico, procedimentos metodológicos do estudo, descrição e análise dos resultados e, por fim, a conclusão.

\section{REFERENCIAL TEÓRICO}

\subsection{Governança Eletrônica e Teoria das Escolhas Públicas}

A teoria da escolha pública, desenvolvida na década de 60 , considera que tanto os agentes públicos quanto os agentes econômicos realizam seus fins privados e entre estes está a perseguição de rendas dentro da sociedade (BUCHANAN; TULLOCK, 1962). O principal argumento da Public Choice é de que os indivíduos são motivados pelos interesses próprios (DIAS, 2009). A escolha pública incorpora uma compreensão sobre a natureza humana, e propõe a análise por meio do estudo de elementos que compõem a interferem na tomada de decisões pelos agentes públicos (BUCHANAN, 2003).

Uma das principais críticas a respeito da teoria da escolha pública é que os resultados políticos diferem dos resultados de mercado, sendo que as diferenças não decorrem das motivações comportamentais dos indivíduos, mas das estruturas institucionais dentro das quais os racionais buscam alcançar ou atingir interesses (COSTA et al., 2013). Segundo Cruz (2010), a teoria da escolha pública tem perspectiva notadamente "racional" para inferir sobre as motivações que influenciam a tomada de decisões no ambiente político. Na medida em que o indivíduo racional é capaz de prever o impacto de suas escolhas, ele vai tentar 
escolher uma regra de tomada de decisão que irá minimizar os custos esperados que ele deve incorrer. (BUCHANAN, 2011).

Supõe-se que os atores políticos tomam decisões considerando interesses pessoais, é possível assumir que esta teoria contribui para explicar a maneira pela qual os governos tomam decisões acerca de impostos, despesas, políticas públicas, entre outros (CRUZ, 2010). Assim, relacionar a teoria da escolha pública com a governança eletrônica é importante, visto que pode apresentar explicações importantes sobre as decisões dos gestores a respeito da governança pública e eletrônica, uma vez que a mesma surge para impor regras, procedimentos e instituições para evitar o abuso de poder e as tentações políticas (PEREIRA, 1997).

A governança eletrônica ou e-governança pode ser entendida como a aplicação dos recursos das TICS na gestão pública para fornecer serviços e informações e promover maior participação cidadã. Nesse sentido, entende-se que a governança eletrônica é composta pelo governo eletrônico e democracia eletrônica (MELLO, 2009).

O governo eletrônico implica uma entrega de informações e serviços governamentais por meios eletrônicos. Composto pela administração eletrônica (utilização das TICs na criação de repositórios de dados para os sistemas de informações gerenciais, bem como informatização dos registros e serviços eletrônicos e prestação de serviços on-line) e pelos serviços eletrônicos, o governo eletrônico é entendido como todas as ações modernizadoras em conjunto vinculadas à administração pública, que passaram a ganhar notoriedade no final dos anos 90 (REZENDE; FREY, 2005; DINIZ et al., 2009; MELLO, 2009).

A democracia eletrônica caracteriza-se pela utilização dos recursos das TICs para promover o aumento do grau e da qualidade da participação pública do governo. Assim, os mecanismos de participação democrática proporcionados pelas novas tecnologias representam a possibilidade de alargamento do espaço público e a consequente inserção organizada de setores diversos nos processos de definição de políticas públicas, pressuposto reconhecido pelas diretrizes de governo eletrônico, que afirmam o papel do Estado na gestão tecnológica de maneira a incentivar formas participativas de realização da democracia digital (ROTHBERG, 2008; MELLO, 2009).

\subsection{Relação da governança com indicadores socioeconômicos, contábeis e de transparência}

\subsubsection{Relação da governança com as características socioeconômicas}

As boas práticas de governança eletrônica podem ser explicadas por fatores socioeconômicos, tais como aqueles representados pelas variáveis PIB (Produto Interno Bruto), IDH (Índice de Desenvolvimento Humano) e habitantes do município, conforme foi constatado no estudo realizado por Moura et al. (2015) nos municípios do estado de Santa Catarina. Já Huther e Shah (1999) encontraram correlações de 7\% e 14\% entre um índice de governança eletrônica e PIB e IDH, em 80 países espalhados em diversos continentes. Moura et al. (2015) replicaram a metodologia de Mello (2009), em que os resultados indicaram que os entes da federação com maior desenvolvimento socioeconômico foram os mais bem classificados (com maiores práticas de governança eletrônica implantadas).

Esta afirmação é corroborada por Evangelista et al. (2015), indicando que as pesquisas apontam que os estados e municípios brasileiros desenvolvidos possuem maiores índices de governança eletrônica e que alguns indicadores socioeconômicos (PIB, PIB per capita), sociais (IDH e GINI) e quantidades de habitantes possuem certo grau de relação com 
as práticas de governança implantadas. Além disso, Kaufmann et al. (2005) também encontraram alta correlação entre governança e o IDH.

Assim, cabe destacar as maiores barreiras aos objetivos do Governo Eletrônico de oferecer serviços interativos ao cidadão através da Internet são as limitações de ordem socioeconômica que dificultam o acesso da maioria da população brasileira a sistemas de telefonia e a equipamentos de informática. Entretanto, na outra mão, as barreiras se acrescem de diversos elementos de uma realidade complexa que, em diversos pontos, sinaliza o potencial de programas de governo eletrônico do país (JARDIM, 2007).

Além dos índices já mencionados acima, utilizados em pesquisas anteriores, índices como Índice Firjan de Desenvolvimento Municipal (IFDM) e Índice Firjan de Gestão Fiscal (IFGF) também são considerados na presente pesquisa. O IFDM acompanha três áreas: Emprego e Renda, Educação e Saúde e utiliza-se exclusivamente de estatísticas públicas oficiais (FIRJAN, 2016a). Além disso, sua metodologia possibilita determinar com precisão se a melhora relativa ocorrida em determinado município decorre da adoção de políticas específicas ou se o resultado obtido é apenas reflexo da queda dos demais municípios.

Já o IFGF é composto por cinco indicadores: Receita Própria, Gastos com Pessoal, Investimentos, Liquidez e Custo da Dívida. Uma importante característica do IFGF é que sua metodologia permite tanto comparação relativa quanto absoluta, isto é, o índice não se restringe a uma fotografia anual, podendo ser comparado ao longo dos anos. O IFGF utilizase exclusivamente de estatísticas oficiais declaradas pelos próprios municípios à Secretaria do Tesouro Nacional (STN), de acordo com o estabelecido pela Lei de Responsabilidade Fiscal (LRF) (FIRJAN, 2016b).

Ainda que não seja possível determinar a direção da relação causal da governança eletrônica com estes diversos indicadores socioeconômicos, os estudos anteriores de Huther e Shah (1999), Jardim (2004), Kaufmann et al. (2005), Evangelista et al. (2015) e Moura et al. (2015) demonstram que as características socioeconômicas têm um impacto positivo no índice de governança eletrônica.

\subsubsection{Relação da governança com aspectos contábeis}

A utilização de indicadores no processo de avaliação dos orçamentos busca monitorar a eficiência governamental, enfatizando os resultados obtidos nas atividades realizadas pelo poder público para que sejam detectadas alterações que possam comprometer o planejamento dos recursos públicos (SANTOS; ALVES, 2011).

Dentre eles destacam-se o indicador de realização da receita orçamentária (IRRO), que evidencia o grau de acerto do planejamento e da estimação das receitas constante no orçamento anual, considerando a receita total realizada e a receita total orçada; o indicador da execução orçamentária corrente (IEOC), com a função de evidenciar a capacidade do órgão público em manter suas despesas correntes através das respectivas receitas correntes para o mesmo período; o indicador da realização da receita tributária (IRRT), que evidencia a pressão tributária exercida sobre a riqueza econômica dos municípios, mensuradas através da receita tributária arrecadada em relação ao PIB (Produto Interno Bruto) local no mesmo período; o indicador de operações de crédito (IOC), que evidencia o montante das operações de crédito na composição das despesas de capital (SANTOS; ALVES, 2011).

Ressalta-se a importância de se discutir a respeito do indicador de estrutura de capital. Observa-se, nos últimos anos, que estudar a estrutura de capital assume grande importância no país, não sendo diferente na realidade pública, face às transformações 
ocorridas no ambiente macroeconômico, envolvendo a abertura comercial, a liberalização cambial e a estabilização da moeda (GUSMÃO; RAIFUR; LEMES JÚNIOR, 2008).

O indicador de estrutura de capital mensura a parcela do passivo total que é proveniente de terceiros. De acordo com pesquisas realizadas por Macedo e Corbari (2009), os resultados do efeito da Lei de Responsabilidade Fiscal como mecanismo de restrição fiscal indicam que houve mudança no padrão de endividamento por meio desta variável e da variável "endividamento defasado".

Já o indicador liquidez indica o comprometimento patrimonial e condições de liquidez (MACEDO; CORBARI, 2009). De acordo com os autores, esta variável representa a parcela das obrigações que as disponibilidades podem saldar. $O$ indicador grau de dependência, segundo Macedo e Corbari (2009), consiste na relação entre as receitas de transferência do Estado e da União e a receita total do município, indicando o grau de dependência da administração em relação a recursos de outras esferas governamentais.

$O$ indicador despesas com pessoal demonstra quanto das receitas correntes são comprometidas com despesas de pessoal. Para fins de pesquisa, entende-se como despesas com pessoal os gastos decorrentes de pessoal ativo, inativo e pensionista, mantido pelo ente, bem como os gastos resultantes de mandatos eletivos, cargos em comissão e as demais formas de emprego público entendido como gastos de pessoal pela LRF.

Em estudo realizado por Ribeiro et al. (2012), esta variável mostrou que a elevação do gasto com pessoal ao longo do período analisado nos municípios mineiros mostrou-se como fator positivo para os indicadores de saúde e educação, além de que o controle da despesa com pessoal tem contribuído para a elevação do desenvolvimento social e humano dos municípios estudados (RIBEIRO et al., 2012). Por fim, o indicador de despesas com investimento indica a relação entre as despesas de investimento e a receita corrente líquida (MACEDO; CORBARI, 2009).

Considerando os estudos de Santos e Alves (2011), Gusmão, Raifur, Lemes Júnior (2008), Macedo e Corbari (2009) e Ribeiro et al. (2012), apesar dos autores não abordarem especificamente a relação entre governança eletrônica e indicadores contábeis, os mesmos serão utilizados como base para o desenvolvimento deste trabalho, visto que ainda há poucos estudos nessa área, espera-se que exista relação positiva entre os indicadores contábeis com a governança eletrônica dos estados brasileiros.

\subsubsection{Relação da governança com a transparência}

A transparência na evidenciação dos atos e das contas da gestão pública é uma questão que possui relevância social e que ganhou maior notoriedade no Brasil posteriormente à edição da Lei Complementar no 101/2000 (CRUZ et al., 2012). Neste sentido, o paradigma inovador da governança pública desponta em paralelo com formas inéditas de pensar e agir, apoiadas nas modernas TIC, tornando possível um processo de decisão mais informado e transparente (BRAGA et al., 2014).

Também se destaca, relacionada à transparência, a Lei de Acesso à Informação (Lei no 12.527/2011). O início da validade da lei colocou o desafio de transformá-la em instrumento efetivo de apoio a um governo mais aberto e responsivo (ANGÉLICO, 2012). É notável que se tornou tendência a adoção de dispositivos legais com vistas a proporcionar à população medidas governamentais mais transparentes.

Diante dessa realidade, os códigos internacionais de boas práticas de governança na gestão pública, com destaque para os códigos elaborados pela Organization for Economic Co-operation and Development (OECD), pelo Fundo Monetário Internacional (FMI) e pela 
International Federation of Accountants (IFAC), além de sugerirem as ações que se traduzem em boas práticas, também têm apontado a internet como meio de comunicação com potencialidade de disponibilizar informações de forma tempestiva e transparente aos diversos atores sociais (CRUZ et al., 2012).

Neste sentido, destaca-se o estudo de Cruz et al. (2012) que buscou verificar o nível de transparência das informações acerca da gestão pública divulgadas nos portais eletrônicos de 96 municípios incluídos entre os 100 maiores do Brasil e quais características e indicadores podem contribuir para explicar o nível de transparência observado. As evidências encontradas pelos autores apontam baixos níveis de transparência, considerados incompatíveis com o nível de desenvolvimento socioeconômico dos municípios. Os autores também concluíram que se pode concluir que, no geral, existe associação entre as condições socioeconômicas dos municípios e os níveis de transparência na divulgação de informações acerca da gestão pública, observados nos sites dos grandes municípios brasileiros que compõem a amostra desse estudo.

No estudo realizado por Ribeiro e Zuccolotto (2014), observou-se que a transparência fiscal ainda é incipiente na administração pública, confirmando-se a associação com melhores indicadores de desenvolvimento socioeconômico e fiscal. Em estudo semelhante, Neves, Diniz e Martins (2015), que realizaram uma pesquisa objetivando verificar a relação da transparência pública com o IDH Municipal, nos municípios da Paraíba, concluíram que existe uma relação entre os indicadores socioeconômicos e os níveis de transparência pública, sendo evidenciada pela relação positiva do indicador socioeconômico com as variáveis que compõem o indicador da transparência.

A transparência não está relacionada só com o poder executivo; o estudo de Raupp e Pinho (2011) e Campagnoni et al. (2016) realizaram uma análise dos portais eletrônicos das câmaras de vereadores de municípios brasileiros. Raupp e Pinho (2011) observaram uma baixa capacidade dos portais eletrônicos em contribuir com a prestação de contas e participação dos cidadãos. Campagnoni et al. (2016) observaram que os níveis de transparência ainda não é o que se espera em relação ao poder legislativo brasileiro, o conteúdo apresentado nos portais da transparência cumpre o mínimo exigido pela lei, mas com pouco indício de maiores incentivos à participação popular e à promoção da accountability.

Outro estudo mais recente elaborado por Mota et al. (2017) analisou de que forma a execução orçamentária (receitas e gastos) influenciam a transparência fiscal ativa nos municípios do Estado da Paraíba. Os resultados sugerem que as Receitas de Transferências e os Gastos com Saúde apresentam uma relação negativa com o Índice de Transparência Fiscal Ativa, enquanto a Receita Própria per capita e o Gasto com Pessoal indicam uma relação positiva. Constataram que 0 aumento no recebimento das transferências intergovernamentais estimula um aumento mais que proporcional do gasto público no ente receptor, o que se tem denominado de flypaper effect (Mota et al., 2017).

A transparência apresenta grandes desafios que requerem estratégias explícitas dentro do contexto e leve em conta o desafio das condições socioeconômicas da sociedade. A evidenciação pode ser considerada uma das principais formas de comunicação entre os usuários das informações e as entidades públicas, por isso a transparência se torna tão importante (AVELINO et al., 2014). Assim, a transparência é uma ferramenta de controle, que deve ser utilizada pelos cidadãos, para fiscalizar as ações dos governantes, tanto em nível federal, como estadual e municipal (SOUZA et al., 2010). 
A transparência é uma característica própria da governança. Desde o advento da Lei Complementar no 101/2000 e 131/2009, bem com a Lei de Acesso à Informação (LAI), lei no 12.527/2011, a transparência se mostrou assunto relevante para estudos na área pública. Para tanto, órgãos e pesquisadores já buscaram levantar indicadores para avaliar o nível de transparência dos estados e municípios brasileiros, tais como a Controladoria Geral da União (CGU), com a Escala Brasil Transparente (EBT), o Ministério Público Federal (MPF), com o projeto de combate à corrupção, o Tribunal de Contas do Estado do Paraná (TCE-PR), no projeto LAI Social em 2014. Outros autores também investigaram a relação da transparência com outras variáveis, bem como a análise da própria transparência (BRAGA et al., 2014; CRUZ et al., 2012; ANGÉLICO, 2012; NEVES; DINIZ; MARTINS, 2015).

Ainda que não se tenha estudos específicos abordando a influência da transparência em fatores de governança eletrônica, a partir destes estudos esperou-se que exista uma relação positiva entre os indicadores de transparência e a governança eletrônica dos estados.

Desta maneira, na presente pesquisa os indicadores utilizados para avaliar a relação da transparência com o IGEB serão a Escala Brasil Transparente (EBT), que envolve a regulamentação da Lei de Acesso à Informação (LAI) e a transparência passiva, e o Índice de Transparência, que apresenta como base as Leis Complementares no 101/2000, 131/2009 e Lei $n$ o 12/527/2011, bem como outros dispositivos legais correlacionados à transparência.

\section{PROCEDIMENTOS METODOLÓGICOS}

Este estudo classifica-se como descritivo, utilizando-se de procedimentos documentais, sob uma abordagem quantitativa, utilizando a técnica estatística de regressão linear múltipla com dados em painel.

Para esta pesquisa optou-se pela utilização dos Estados Brasileiros, visto que o índice de governança eletrônica, proposto por Mello (2009), está disponível para o período analisado, 2011 a 2015, já tendo sido validado pelo autor e em outras pesquisas que se utilizaram do mesmo índice.

As variáveis socioeconômicas foram obtidas no site do IBGE e da Firjan. No entanto, pelas características das variáveis, dificuldade de mensuração e trabalho de elaboração, as mesmas não são divulgadas todos os anos, para tanto foi utilizada aquelas disponíveis e calculadas a mediana nos anos em que não há índice calculado.

As variáveis contábeis foram obtidas do portal eletrônico da Secretaria de Tesouro Nacional (STN), mais especificamente do Siconfi, onde o mesmo disponibiliza as demonstrações financeiras dos respectivos Estados. Estes dados têm sido utilizado na maioria de outros estudos (LOURENÇON, 2001; CAMPELLO, 2003; RUCKERT; BORSATTO; RABELO, 2002; SANTOS; ALVES, 2011), sendo a principal fonte de dados contábeis, orçamentários e financeiros dos entes políticos brasileiros.

Foram utilizadas duas variáveis de transparência, a primeira é a EBT, obtida do site da CGU, no entanto, a mesma somente foi calculada recentemente, abrangendo duas edições, para os demais períodos fez-se um cálculo da mediana; a segunda é o índice de transparência do MPF, obtido no seu site, no projeto de combate à corrupção.

A seguir, apresenta-se o Quadro 1 que sintetiza as variáveis dessa pesquisa, facilitando a visualização e compreensão das mesmas. Nesse quadro é possível identificar as variáveis coletadas, sua forma de mensuração, autores e a dimensão a qual pertence, isto é, socioeconômica, contábil e transparência. 
Quadro 1 - Variáveis da pesquisa

\begin{tabular}{|c|c|c|c|}
\hline Dimensão & Código & Mensuração & Autor \\
\hline 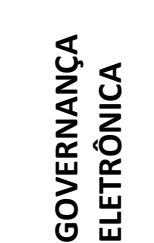 & IGEB & $\begin{array}{l}\text { Índice de Governança Eletrônica dos Estados Brasileiros (IGEB): } \\
\text { Índice que reflete o grau das melhores práticas de governança } \\
\text { eletrônica do ente político estudo, leva em conta as práticas de } \\
\text { conteúdo, serviços, participação cidadã, privacidade e segurança, } \\
\text { usabilidade e acessibilidade. }\end{array}$ & $\begin{array}{l}\text { Mello } \\
\text { (2009) }\end{array}$ \\
\hline \multirow{5}{*}{ 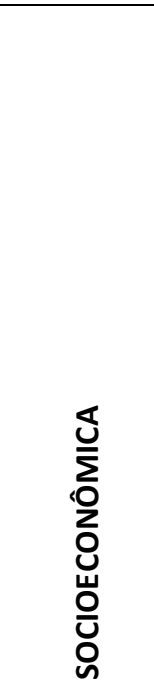 } & POP & População: Quantidade de habitantes do município. & \multirow{5}{*}{$\begin{array}{l}\text { Cruz } \\
\text { (2010); } \\
\text { Cruz, } \\
\text { Ferreira, } \\
\text { Silva } \\
\text { Macedo } \\
(2012)\end{array}$} \\
\hline & PIB & $\begin{array}{l}\text { Produto Interno Bruto: Representa a soma (em valores monetários) } \\
\text { de todos os bens e serviços finais produzidos em um determinado } \\
\text { município. }\end{array}$ & \\
\hline & $\mathrm{IDH}$ & $\begin{array}{l}\text { Índice de Desenvolvimento Humano dos Municípios: Índice que } \\
\text { representa o grau de desenvolvimento humano dos municípios, } \\
\text { tendo como base a longevidade, educação e renda. Sendo: } \\
\sqrt[3]{\left(I_{\text {vida }} \times I_{\text {educação }} \times I_{\text {rendimento }}\right)}\end{array}$ & \\
\hline & IFDM & $\begin{array}{l}\text { Índice Firjan de Desenvolvimento Municipal: Índice que calcula o } \\
\text { desenvolvimento socioeconômicos dos municípios brasileiros, tendo } \\
\text { como base o emprego e renda, educação, saúde. Elaborado pelo } \\
\text { Sistema Firjan. }\end{array}$ & \\
\hline & IFGF & $\begin{array}{l}\text { Índice Firjan de Gestão Fiscal: Índice construído a partir dos } \\
\text { resultados fiscais das próprias prefeituras - informações de } \\
\text { declaração obrigatória e disponibilizadas anualmente pela Secretaria } \\
\text { do Tesouro Nacional (STN). }\end{array}$ & \\
\hline \multirow{6}{*}{ 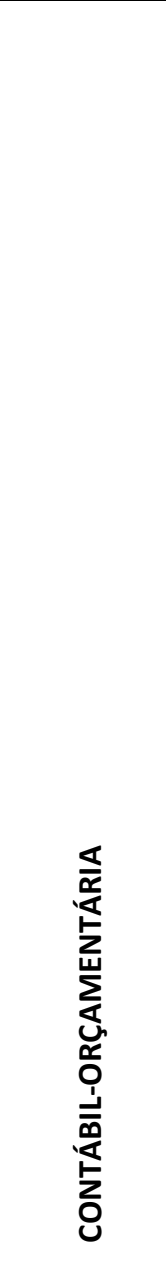 } & IRRO & $\begin{array}{l}\text { Indicador da realização da receita orçamentária (IRRO): evidencia o } \\
\text { grau de acerto do planejamento e da estimação das receitas, } \\
\text { considerando a receita total realizada e a receita total orçada: } \\
I R R O=R T R / R T O \\
\text { Onde: IRRO = Indicador da realização da receita orçamentária; } R T R= \\
\text { Receita Total Realizada; } R T O=\text { Receita total orçada. }\end{array}$ & $\begin{array}{l}\text { Lourençon } \\
\text { (2001) }\end{array}$ \\
\hline & IEOC & $\begin{array}{l}\text { Indicador da execução orçamentária corrente (IEOC): evidencia a } \\
\text { capacidade do órgão público em manter suas despesas correntes } \\
\text { através das respectivas receitas correntes para o mesmo período: } \\
I E O C=R C R / D C R \\
\text { Onde: IEOC = Indicador da execução orçamentária corrente; } R C R= \\
\text { Receita corrente realizada; } D C R=\text { Despesa corrente realizada. }\end{array}$ & $\begin{array}{l}\text { Campello } \\
\text { (2003), } \\
\text { Ruckert, } \\
\text { Borsatto e } \\
\text { Rabelo } \\
(2002)\end{array}$ \\
\hline & IRRT & $\begin{array}{l}\text { Indicador da realização da receita tributária (IRRT): evidencia a } \\
\text { pressão tributária exercida sobre a riqueza econômica dos } \\
\text { municípios, mensuradas através da receita tributária arrecadada em } \\
\text { relação ao PIB (Produto interno bruto local): } I R R T=R T R / P I B l \\
\text { Onde: IRRT = Indicador da realização da receita tributária; } R T R= \\
\text { Receitas tributárias realizadas; } P I B I=\text { Produto interno bruto local. }\end{array}$ & $\begin{array}{l}\text { López } \\
\text { Corrado } \\
\text { (2005) }\end{array}$ \\
\hline & $\mathrm{IOC}$ & $\begin{array}{l}\text { Indicador de operações de crédito (IOC): evidencia o montante das } \\
\text { operações de crédito na composição das despesas de capital: } \\
I O C=O C R / D C R \\
\text { Onde: } O C R=\text { Operações de crédito realizadas; } D C R=\text { Despesas de } \\
\text { capital realizadas. }\end{array}$ & $\begin{array}{l}\text { Santos } \\
\text { Alves } \\
(2011)\end{array}$ \\
\hline & IEC & $\begin{array}{l}\text { Indicador de Estrutura de Capital (IEC): indica a parcela do passivo } \\
\text { total que é proveniente de terceiros. Sendo: } I E C=\frac{P F+P P}{A T} \\
\text { Onde: PF=Passivo Financeiro; PP=Passivo Permanente; AT= Ativo } \\
\text { Total. }\end{array}$ & \multirow[t]{2}{*}{$\begin{array}{l}\text { Macedo } \\
\text { Corbari } \\
(2009)\end{array}$} \\
\hline & ILIQ & Indicador de Liquidez (ILIQ): indica o comprometimento & \\
\hline
\end{tabular}




\begin{tabular}{|c|c|c|c|}
\hline & & $\begin{array}{l}\text { patrimonial e as condições de liquidez. Sendo: } I L I Q=\frac{A F}{P F} \\
\text { Onde: } A F=\text { Ativo Financeiro: } P F=\text { Passivo Financeiro }\end{array}$ & \\
\hline & IGD & $\begin{array}{l}\text { Indicador do Grau de dependência (IGD): indica o grau de } \\
\text { dependência da administração municipal em relação às } \\
\text { transferências recebidas. Sendo: } \\
\text { IGD }=\frac{R T r a n s}{R T} \\
\text { Onde: RTrans= Receita de Transferência; RT= Receita Total. }\end{array}$ & \\
\hline & IDP & $\begin{array}{l}\text { Indicador de Despesas com Pessoal (IDP): Indica quanto das receitas } \\
\text { correntes são comprometidas às despesas com pessoal. Sendo: } \\
I D P=\frac{P e s+E n c}{R C L} \\
\text { Onde: Pes= Pessoal; Enc= Encargos; } \mathrm{RCL}=\text { Receita Corrente Líquida. }\end{array}$ & \\
\hline & IDI & $\begin{array}{l}\text { Indicador de Despesas com Investimento (IDI): indica a relação } \\
\text { entre as Despesas de Investimento e a Receita Corrente Líquida: } \\
\text { Sendo: } I D I=\frac{G I}{R C L} \\
\text { Onde: } \mathrm{GI}=\text { Gastos de Investimento; } \mathrm{RCL}=\text { Receita Corrente Líquida. }\end{array}$ & \\
\hline \multirow[b]{2}{*}{ 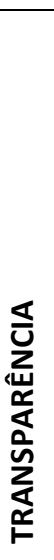 } & EBT & $\begin{array}{l}\text { Escala Brasil Transparente (EBT): Checklist EBT, que envolve } \\
\text { regulamentação LAI e transparência passiva. A Escala Brasil } \\
\text { Transparente (EBT) é uma metodologia para medir a transparência } \\
\text { pública em estados e municípios brasileiros. Indicador que tem o } \\
\text { objetivo de avaliar o grau de cumprimento de dispositivos da Lei de } \\
\text { Acesso à Informação (LAI). }\end{array}$ & \multirow{2}{*}{$\begin{array}{l}\text { Cruz } \\
(2010) \\
\text { Fiirst et al. } \\
(2017)\end{array}$} \\
\hline & I_Transp. & $\begin{array}{l}\text { Índice de Transparência: o índice toma como base as LC 101/2000, } \\
\text { LC 131/2009, e lei no 12/527/2011, bem como outros dispositivos } \\
\text { legais correlacionados com a transparência. Os itens avaliados no } \\
\text { que se refere à transparência são informações sobre receita, } \\
\text { despesa, licitações e contratos, relatórios, serviço de informação ao } \\
\text { cidadão presencial (SIC) e eletrônico (e-SIC), divulgação da estrutura } \\
\text { e forma de contato e, por fim, boas práticas de transparência. }\end{array}$ & \\
\hline
\end{tabular}

Fonte: Os Autores (2016)

Foi utilizada a regressão linear múltipla como técnica estatística para esta pesquisa para a análise da influência entre as variáveis independentes e a dependente. Como se trata de uma análise de cinco anos, abrangendo diversas variáveis, essa análise é caracterizada como uma regressão através de dados em painel.

O estudo envolveu uma variável dependente e 14 independentes, sendo cinco variáveis socioeconômicas, nove variáveis contábeis e duas variáveis de transparência. Dessa forma, estabeleceu-se três modelos de regressão, um para cada um dos constructos que será analisado. Os modelos da regressão são assim definidos:

$$
\begin{aligned}
& I G E B_{i t}=\beta_{i}+\beta_{1} P O P_{i t}+\beta_{2} P I B_{I T}+\beta_{3} I D H E_{i t}+\beta_{4} I F D M_{i t}+\beta_{5} I F G F_{i t}+\epsilon_{i t \ldots} \\
& \text { (equação 1) } \\
& I G E B_{i t}=\beta_{i}+\beta_{1} I R R O_{i t}+\beta_{2} I E O C_{i t}+\beta_{3} I R R T_{i t}+\beta_{4} I O C_{i t}+\beta_{5} I E C_{i t}+\beta_{6} I L I Q_{i t}+ \\
& \beta_{7} I G D_{i t}+\beta_{8} I D P_{i t}+\beta_{9} I D I_{i t}+\epsilon_{i t \ldots} \\
& I_{G E B_{i t}}=\beta_{i}+\beta_{1} E B T_{i t}+\beta_{2} I_{-} \text {transp }_{i t}+\epsilon_{i t \ldots}
\end{aligned}
$$

Esperou-se que os coeficientes fossem estatisticamente significativos, e que os coeficientes de cada uma das equações fossem positivos, isto é, esperou-se que exista uma relação positiva entre as características socioeconômicas, contábeis e de transparência e a governança eletrônica dos estados brasileiros. Além disso, realizou-se diversos testes para confirmar os pressupostos destes modelos, tais como teste de Breusch-Pagan, F de Chow, 
Hausman para verificar o efeito dos dados em painel, o teste de Durbin-Watson para verificar problemas de auto correlação, o teste VIF para identificar se há problemas de multicolinearidade e o teste White para verificar se tem problema de heterocedasticidade nos resíduos.

Tendo em vista o procedimento estatístico necessário para o desenvolvimento deste trabalho, como exemplo o cálculo da regressão de dados em painel, utilizou-se dos softwares estatísticos Stata ${ }^{\circledR}$ e Office Excel ${ }^{\circledR}$.

É necessário mencionar que em alguns anos não serão obtidos todos os dados necessários, visto que alguns não estarão disponíveis nos portais, para tanto, utiliza-se da média e mediana para alcançar um valor aproximado. Outra possível limitação seria quanto a metodologia, pois as diversas variáveis se referem a anos diferentes, como 2010, 2013, 2015 , no entanto as mesmas são as mais atualizadas que podem ser obtidas.

\section{DESCRIÇÃO E ANÁLISE DOS RESULTADOS}

\subsection{Relação da governança com as características socioeconômicas}

Foi feito o painel evidenciado na Tabela 1 considerando todas as variáveis socioeconômicas, e observou-se que as variáveis não são estatisticamente significativas ao nível de significância (P-value) de $5 \%$, o que não permitiu analisar o modelo 1 , a qual buscava observar a existência de influência de características socioeconômicas na governança eletrônica dos estados.

Tabela 1 - A influência das características socioeconômicas na governança eletrônica dos estados brasileiros (regressão geral)

\begin{tabular}{|c|c|c|c|c|c|c|c|c|c|c|c|}
\hline Prob $>F$ & $\mathbf{R}^{\mathbf{2}}$ & VIF & DV & & $\begin{array}{l}\text { Teste } \\
\text { BP/CW }\end{array}$ & $\begin{array}{l}\text { Teste } \\
\text { White }\end{array}$ & $\begin{array}{l}\text { Teste } \\
\text { B e P }\end{array}$ & $\begin{array}{l}\text { F de } \\
\text { Chow }\end{array}$ & \multicolumn{2}{|c|}{$\begin{array}{l}\text { Teste } \\
\text { Hausman }\end{array}$} & № OBS \\
\hline 0.0000 & 0.4268 & 18.44 & & & 0.2050 & .0786 & 0.0000 & 0.0000 & \multicolumn{2}{|c|}{0.0586} & 135 \\
\hline \multirow{2}{*}{\multicolumn{2}{|c|}{ Variáveis Indep. }} & \multicolumn{10}{|c|}{ Painel com Efeitos Aleatórios } \\
\hline & & \multicolumn{2}{|c|}{ Coeficiente } & \multicolumn{2}{|c|}{ Erro Padrão } & $T$ & P-Value & \multicolumn{4}{|c|}{ Interv. Conf. 95\% } \\
\hline \multicolumn{2}{|l|}{ POP } & \multicolumn{2}{|c|}{-.2995639} & \multicolumn{2}{|c|}{2.748782} & -0.11 & 0.913 & \multicolumn{2}{|c|}{-5.738096} & \multicolumn{2}{|c|}{5.138968} \\
\hline PIB & & \multicolumn{2}{|c|}{4.411325} & \multicolumn{2}{|c|}{2.514599} & 1.75 & 0.082 & \multicolumn{2}{|c|}{-.5638708} & \multicolumn{2}{|c|}{9.38652} \\
\hline \multicolumn{2}{|l|}{ IDHE } & \multicolumn{2}{|c|}{-38.74876} & \multicolumn{2}{|c|}{36.92718} & -1.05 & 0.296 & \multicolumn{2}{|c|}{-111.8101} & \multicolumn{2}{|c|}{34.31256} \\
\hline \multicolumn{2}{|l|}{ IFDM } & \multicolumn{2}{|c|}{15.12227} & \multicolumn{2}{|c|}{13.15161} & 1.15 & 0.252 & \multicolumn{2}{|c|}{-10.89851} & \multicolumn{2}{|c|}{41.14305} \\
\hline \multicolumn{2}{|l|}{ IFGF } & \multicolumn{2}{|c|}{10.12583} & \multicolumn{2}{|c|}{7.811722} & 1.30 & 0.197 & \multicolumn{2}{|c|}{-5.329854} & \multicolumn{2}{|c|}{25.58151} \\
\hline \multicolumn{2}{|l|}{ cons } & \multicolumn{2}{|c|}{-4.062685} & \multicolumn{2}{|c|}{18.51788} & -0.22 & 0.827 & \multicolumn{2}{|c|}{-40.70077} & \multicolumn{2}{|c|}{32.5754} \\
\hline
\end{tabular}

Fonte: Os Autores (2016)

É importante observar que ao contrário do que se esperava, não foi possível testar a hipótese de que características socioeconômicas tem influência positiva na governança eletrônica, visto que estudos como os de Huther e Shah (1999), Jardim (2004), Kaufmann et al. (2005), Evangelista, Rodrigues e Krauter (2015), Moura et al. (2015) associavam o IDH com altos índices de governança, até mesmo o PIB seria uma medida associada a uma boa governança, este, por sua vez, no estudo, mostrou-se significativo ao nível de 10\%, além de outros estudos que acreditam que alto crescimento, desenvolvimento, investimentos em educação, saúde, renda teriam associação positiva com bons índices de governança. Dessa forma, acredita-se que o tamanho da amostra e pelas características dos dados de cada indicador socioeconômicos afetaram a significância dessas variáveis.

\subsection{Relação da governança com aspectos contábeis}


O segundo painel (Tabela 2) considera todas as variáveis contábeis deste modelo, significativas ou não. Observa-se que somente as variáveis IRRO, IEOC, IOC, IGD e IDP foram significantes ao nível de $5 \%$, o que permitiu separá-las para proceder aos testes específicos, bem como a análise dos respectivos pressupostos.

Tabela 2 - A influência dos indicadores contábeis na governança eletrônica dos estados brasileiros (regressão geral)

\begin{tabular}{|c|c|c|c|c|c|c|c|c|c|c|c|}
\hline Prob $>F$ & $\mathbf{R}^{\mathbf{2}}$ & VIF & DI & & $\begin{array}{l}\text { Teste } \\
\text { BP/CW }\end{array}$ & $\begin{array}{l}\text { Teste } \\
\text { White }\end{array}$ & $\begin{array}{l}\text { Teste } \\
\text { B e P }\end{array}$ & $\begin{array}{l}\text { F de } \\
\text { Chow }\end{array}$ & \multicolumn{2}{|c|}{$\begin{array}{l}\text { Teste } \\
\text { Hausman }\end{array}$} & № OBS \\
\hline 0.0000 & 0.3816 & 1.47 & \multicolumn{2}{|c|}{1.575383} & 0.0095 & .908 & 0.0000 & 0.0000 & \multicolumn{2}{|c|}{0.0066} & 135 \\
\hline \multirow{2}{*}{\multicolumn{2}{|c|}{ Variáveis Indep. }} & \multicolumn{10}{|c|}{ Painel com Efeitos Fixos } \\
\hline & & \multicolumn{2}{|c|}{ Coeficiente } & \multicolumn{2}{|c|}{ Erro Padrão } & $T$ & P-Value & \multicolumn{4}{|c|}{ Interv. Conf. 95\% } \\
\hline \multicolumn{2}{|l|}{ IRRO } & \multicolumn{2}{|c|}{-2.273735} & \multicolumn{2}{|c|}{.3371031} & -6.74 & 0.000 & \multicolumn{2}{|c|}{-2.940903} & \multicolumn{2}{|c|}{-1.606566} \\
\hline \multicolumn{2}{|l|}{ IEOC } & \multicolumn{2}{|c|}{-15.94924} & \multicolumn{2}{|c|}{6.80517} & -2.34 & 0.021 & \multicolumn{2}{|c|}{-29.41751} & \multicolumn{2}{|c|}{-2.480964} \\
\hline \multicolumn{2}{|l|}{ IRRT } & \multicolumn{2}{|c|}{.0389435} & \multicolumn{2}{|c|}{.037743} & 1.03 & 0.304 & \multicolumn{2}{|c|}{-.0357546} & \multicolumn{2}{|c|}{.1136416} \\
\hline \multicolumn{2}{|l|}{ IOC } & \multicolumn{2}{|c|}{-4.610052} & \multicolumn{2}{|c|}{1.903921} & -2.42 & 0.017 & \multicolumn{2}{|c|}{-8.378149} & \multicolumn{2}{|c|}{-.8419553} \\
\hline \multicolumn{2}{|l|}{ IEC } & \multicolumn{2}{|c|}{-.449795} & \multicolumn{2}{|c|}{.2564057} & -1.75 & 0.082 & \multicolumn{2}{|c|}{-.9572537} & \multicolumn{2}{|c|}{.0576638} \\
\hline \multicolumn{2}{|l|}{ ILIQ } & \multicolumn{2}{|c|}{-.2066877} & \multicolumn{2}{|c|}{.1785675} & -1.16 & 0.249 & -.56009 & & .1467 & \\
\hline IGD & & -20. & & 4.0 & 2073 & -5.03 & 0.000 & -28.418 & & -12.3 & \\
\hline IDP & & -13. & & 6.8 & 8229 & -1.98 & 0.050 & -27.242 & & -.016 & \\
\hline IDI & & .907 & & 1.6 & 2492 & 0.56 & 0.577 & -2.3036 & & $4.11 \varepsilon$ & \\
\hline Cons & & 92.5 & & 9.5 & 3185 & 9.73 & 0.000 & 73.723 & & 111.3 & \\
\hline
\end{tabular}

Fonte: Os Autores (2016)

Fez-se um novo painel para o modelo com as variáveis significativas representativas do modelo. Este método permitiu obter um modelo significante ao nível de $1 \%$, conforme evidenciado na Tabela 3.

Tabela 3 - A influência dos indicadores contábeis na governança eletrônica dos estados brasileiros (regressão específica)

\begin{tabular}{|c|c|c|c|c|c|c|c|c|c|c|c|}
\hline Prob $>F$ & $\mathbf{R}^{\mathbf{2}}$ & VIF & DV & & $\begin{array}{l}\text { Teste } \\
\text { BP/CW }\end{array}$ & $\begin{array}{l}\text { Teste } \\
\text { White }\end{array}$ & $\begin{array}{l}\text { Teste } \\
\text { B e P }\end{array}$ & $\begin{array}{l}\text { F de } \\
\text { Chow }\end{array}$ & \multicolumn{2}{|c|}{\begin{tabular}{|l} 
Teste \\
Hausman \\
\end{tabular}} & № OBS \\
\hline 0.0000 & 0.3624 & 1.14 & & & 0.0033 & .8459 & 0.0000 & 0.0000 & \multicolumn{2}{|c|}{0.1263} & 135 \\
\hline \multirow{2}{*}{\multicolumn{2}{|c|}{ Variáveis Indep. }} & \multicolumn{10}{|c|}{ Painel com Efeitos Aleatórios } \\
\hline & & \multicolumn{2}{|c|}{ Coeficiente } & \multicolumn{2}{|c|}{ Erro Padrão } & $T$ & P-Value & \multicolumn{4}{|c|}{ Interv. Conf. 95\% } \\
\hline IRRO & & \multicolumn{2}{|c|}{-2.190409} & \multicolumn{2}{|c|}{.3047688} & -7.19 & 0.000 & \multicolumn{2}{|c|}{-2.793402} & \multicolumn{2}{|c|}{-1.587416} \\
\hline IEOC & & \multicolumn{2}{|c|}{-15.69152} & \multicolumn{2}{|c|}{6.719451} & -2.34 & 0.021 & \multicolumn{2}{|c|}{-28.98612} & \multicolumn{2}{|c|}{-2.396919} \\
\hline $\mathrm{IOC}$ & & \multicolumn{2}{|c|}{-4.392271} & \multicolumn{2}{|c|}{1.84101} & -2.39 & 0.018 & \multicolumn{2}{|c|}{-8.034754} & \multicolumn{2}{|c|}{-.7497878} \\
\hline IGD & & \multicolumn{2}{|c|}{-22.08378} & \multicolumn{2}{|c|}{4.002839} & -5.52 & 0.000 & \multicolumn{2}{|c|}{-30.0035} & \multicolumn{2}{|c|}{-14.16407} \\
\hline IDP & & \multicolumn{2}{|c|}{-14.32117} & \multicolumn{2}{|c|}{7.076314} & -2.02 & 0.045 & \multicolumn{2}{|c|}{-28.32183} & \multicolumn{2}{|c|}{-.3205058} \\
\hline cons & & \multicolumn{2}{|c|}{94.91284} & \multicolumn{2}{|c|}{9.144668} & 10.38 & 0.000 & \multicolumn{2}{|c|}{76.81989} & \multicolumn{2}{|c|}{113.0058} \\
\hline
\end{tabular}

Fonte: Os Autores (2016)

Os resultados dos testes Breusch-Pagan (0,0000), F de Chow $(0,0000)$ e Hausman $(0,1263)$, apresentado na Tabela 03, indica que a modelagem apropriada para análise da amostra estudada com dados em painel é de efeitos aleatórios, pois o teste de BreuschPagan apresentou-se menor que 0,05, o que consequentemente levou-se a verificar o teste de Hausman, que sinalizou-se maior que 0,05.

Observa-se que a modelagem utilizada mostra-se consistente, uma vez que o modelo composto por 135 observações apresenta-se significante ao nível de $1 \%$. O R ${ }^{2}$, sendo este o 
poder explicativo do modelo é de $36 \%$, o que demonstra que as variáveis independentes (IRRO, IEOC, IOC, IGD, IDP), são capazes de explicar a dependente (IGEB). O modelo não apresenta problemas de auto correlação, uma vez que o Durbin-Watson é de 1,561498, além de não haver problemas de multicolinearidade, conforme aponta o teste VIF $(1,14)$. O teste de Breusch-Pagan/Cook-Weisberg $(0,0033)$ e o teste de White $(0,8459)$, indicam não ter problemas de heterocedasticidade nos resíduos, no entanto, para confiabilidade e robustez, aplicou-se a correção robusta de White.

As variáveis IRRO, IEOC, IOC, IGD e IDP apresentaram-se com significância ao nível de $5 \%$, pois todas possuem um sig. (P-value) menor que 0,05.

Através dos resultados da regressão percebeu-se que a variável IRRO, que evidencia o grau de acerto de planejamento e da estimação de receitas, apresenta influência negativa com a variável dependente governança eletrônica (coeficiente -2.190409). Isso significa que nem sempre os estados que possuem maior acerto orçamentário possuem melhor governança, isso pode estar associado a efetivação do mecanismo de governança implantada, ela pode estar implantada, mas na prática pode não estar funcionando.

Analisando a variável IEOC, que representa a capacidade de um ente público em manter suas despesas correntes por meio das próprias receitas correntes em determinado período, verifica-se que também apresentou coeficiente de regressão negativo (coeficiente -15.69152), o que permite entender que aqueles municípios que utilizam outros tipos de receitas, que nãos as correntes, para manter suas despesas correntes, são os que normalmente apresentariam um grau de governança eletrônica maior. Portanto, mais uma vez, aqueles entes que conseguem cumprir com suas despesas correntes por meio das receitas correntes, não são necessariamente aqueles com índices de governança eletrônica melhor.

O Indicador de Operações de Crédito (IOC) demonstra o percentual compromissos financeiros realizados em um determinado período em relação as despesas de capital executadas. Na regressão, observou-se uma relação negativa entre esta variável e a governança eletrônica (coeficiente -4.392271), o que leva a indícios que municípios que utilizam mais operações de crédito para execução de suas despesas de capital, normalmente apresentam um nível de governança menor. Essa conclusão parece razoável, visto que a utilização desses instrumentos se dá por insuficiências de caixa ou outros motivos correlacionados, assim estes entes tenderiam a se mostrarem com um nível de governança menor, o que significa que possivelmente seriam menos transparentes e atenderiam menos aos anseios de serviços e atendimento à população pela sua governança eletrônica.

O IGD, que representa o grau de dependência de transferências recebidas por outros entes, também se mostrou com coeficiente de regressão negativo (coeficiente -22.08378), o que demonstra uma relação inversa com a governança eletrônica dos estados. Assim, os estados brasileiros que dependem mais das transferências recebidas da União para compor sua receita total, apresentam um índice de governança menor. Essa conclusão pode levar a algumas suposições, por exemplo, estados que apresentam um menor índice de receitas próprias são aqueles com nível de desenvolvimento menor, e, justamente, por isso, faltaria recursos para investir em tecnologias de informação e comunicação (TIC), ou então, o interesse por oferecerem aos cidadãos serviços de qualidade, informação confiável e mais conhecimento, através das TIC, é baixo justamente por não existir demandas da sociedade e o gestor fazer suas escolhas públicas pensando sem o interesse público.

Outra variável contábil que também se mostrou significativa foi o IDP, que representa o quanto das despesas de pessoal são comprometidas com as receitas correntes líquidas do 
ente público. Da mesma forma que as demais variáveis contábeis, também teve influência negativa (coeficiente -14.32117). Isso significa que quando existem mais gastos com pessoal e outros encargos comprometendo sua receita corrente, os estados tendem a se mostrarem com uma governança eletrônica menor, e da mesma forma o contrário.

Observar os resultados das variáveis contábeis é importante, visto que a Teoria da Escolha Pública, onde os agentes ou gestores públicos que buscariam representar a sociedade, nem sempre visam tão somente o interesse público. O IOC representa o quanto um ente público utiliza recursos por meio das operações de crédito, o que demonstra na prática que não necessariamente é direcionado ao interesse público e que poderia prejudicar a imagem desse agente, o que corrobora com a Teoria da Escolha Pública, que diz que os indivíduos são movidos por auto interesse (DOWNS, 1999; DIAS, 2009).

Da mesma forma o IGD, quando o estado tem uma dependência maior de recursos de terceiros demonstra que suas receitas próprias não são tão significativas, dependendo de um terceiro, que nesse caso seria a União. Essa constatação reflete o que se tem denominado de flypaper effect, uma vez que no Brasil muitos recursos são transferidos sem uma condição pré-definida, o que faz com que o aumento desses recebimentos estimula o aumento mais que proporcional do gasto público no ente receptor, por reduz a accountability e a responsabilidade fiscal (MOTA et al., 2017).

Outro resultado que poderia ser explicado por essa teoria, é a relação de influência negativa entre o IDP e a governança, visto que quando existem muitos gastos com pessoal, outros serviços que atenderiam aos anseios da sociedade são prejudicados, então as escolhas públicas não estariam direcionadas para investir na relação entre governo, cidadão e empresas, por meio eletrônico, o que vai ao encontro com o que argumenta Frant (1996), que a estrutura de governança pública teria com o objetivo justamente minimizar os efeitos na relação entre o Estado e os cidadãos.

Nesses casos, é importante continuar com os estudos que investiguem a relação sob a ótica da Teoria da Escolha Pública, visto que o intuito desse trabalho é iniciar a discussão da relação de influência entre características socioeconômicas, contábeis e de governança.

Por fim, percebe-se que existe influência negativa entre os indicadores contábeis e o IGEB nos estados brasileiros.

\subsection{Relação da governança com a transparência}

O terceiro painel (Tabela 4) considera todas as variáveis de transparência do modelo, significativas ou não. Percebe-se que nem todas variáveis foram significativas, considerando um nível de $5 \%$, somente a variável EBT, o que permitiu separá-la da regressão para realizar o teste específico e dos pressupostos respectivos.

Tabela 4 - A influência da transparência na governança eletrônica dos estados brasileiros (regressão geral)

\begin{tabular}{l|l|l|l|l|l|l|l|l|l}
\hline Prob>F & $\mathbf{R}^{\mathbf{2}}$ & VIF & DW & $\begin{array}{l}\text { Teste } \\
\text { BP/CW }\end{array}$ & $\begin{array}{l}\text { Teste } \\
\text { White }\end{array}$ & $\begin{array}{l}\text { Teste } \\
\text { B e P }\end{array}$ & $\begin{array}{l}\mathbf{F} \text { de } \\
\text { Chow }\end{array}$ & $\begin{array}{l}\text { Teste } \\
\text { Hausman }\end{array}$ & No OBS \\
\hline 0.0011 & 0.0827 & 1.07 & 1.623588 & 0.2301 & 0.0656 & 0.0000 & 0.0000 & 0.4183 & 135 \\
\hline \multirow{2}{*}{$\begin{array}{l}\text { Variáveis Indep. } \\
\text { EBT }\end{array}$} & Painel com Efeitos Aleatórios \\
\cline { 2 - 9 } & Coeficiente & Erro Padrão & $\boldsymbol{T}$ & P-Value & Interv. Conf. 95\% \\
\hline I_Transp & .5757455 & .2310664 & 2.49 & 0.014 & .1186733 & 1.032818 \\
\hline _cons & .6446038 & .339595 & 1.90 & 0.060 & -.0271488 & 1.316356 \\
\hline
\end{tabular}

Fonte: Os Autores (2016) 
Assim, fez-se um novo painel com a variável significativa representativas do modelo. Este método permitiu obter um modelo significante ao nível de $1 \%$, conforme evidenciado na Tabela 5.

Tabela 5 - A influência da transparência na governança eletrônica dos estados brasileiros (regressão específica)

\begin{tabular}{l|l|l|l|l|l|l|l|l|l}
\hline Prob>F & $\mathbf{R}^{2}$ & VIF & DW & $\begin{array}{l}\text { Teste } \\
\text { BP/CW }\end{array}$ & $\begin{array}{l}\text { Teste } \\
\text { White }\end{array}$ & $\begin{array}{l}\text { Teste } \\
\text { B e P }\end{array}$ & $\begin{array}{l}\text { F de } \\
\text { Chow }\end{array}$ & $\begin{array}{l}\text { Teste } \\
\text { Hausman }\end{array}$ & No OBS \\
\hline 0.0017 & 0.0569 & 1.00 & 1.615229 & 0.0106 & 0.0398 & 0.0000 & 0.0000 & 0.1927 & 135 \\
\hline \multirow{2}{*}{ ariáveis Indep. } & Painel com Efeitos Aleatórios \\
\cline { 2 - 9 } & Coeficiente & Erro Padrão & $T$ & P-Value & Interv. Conf. $95 \%$ & \\
\hline EBT & .7016241 & .2194503 & 3.20 & 0.002 & .26756 & 1.135688 \\
\hline cons & 53.64597 & 1.428289 & 37.56 & 0.000 & 50.82087 & 56.47107 \\
\hline
\end{tabular}

Fonte: Os Autores (2016)

Os resultados dos testes Breusch-Pagan (0,0000), F de Chow $(0,0000)$ e Hausman $(0,1927)$, indica que a modelagem apropriada para análise da amostra estudada com dados em painel é de efeitos aleatórios, pois o teste de Breusch-Pagan apresentou-se menor que 0,05, o que consequentemente levou-se a verificar o teste de Hausman, que sinalizou-se maior que 0,05 .

Observa-se na Tabela 5, que a modelagem utilizada a fim de verificar a influência da transparência sobre a governança eletrônica dos estados brasileiros (equação 03), mostra-se consistente, uma vez que o modelo composto por 135 observações apresenta-se significante ao nível de $1 \%$. O $\mathrm{R}^{2}$, sendo este o poder explicativo do modelo, é de $5 \%$, o que pode ser considerado baixo, mas é importante ressaltar que somente foi considerado uma variável, justificando um baixo poder explicativo. A variável independente EBT é capaz de explicar a dependente (IGEB). O modelo não apresenta problemas de auto correlação, uma vez que o Durbin-Watson é de 1,615229, além de não haver problemas de multicolinearidade, conforme aponta o teste VIF $(1,00)$ pois possuem apenas uma variável. O teste White $(0,0398)$, indica ter problemas de heterocedasticidade nos resíduos, o que justificou aplicar a correção robusta de White.

A EBT é uma escala que mede o grau de cumprimento da Lei de Acesso à Informação, associando os municípios e estados brasileiros a um indicador de transparência. Na análise do coeficiente de regressão dessa variável, percebeu-se que a mesma influencia o IGEB de maneira positiva. Essa conclusão também é pertinente, visto que quando se fala em governança eletrônica logo se associa com a transparência. Deste modo, os estados que cumprem a Lei de Acesso à Informação têm uma relação com os cidadãos por meios dos mecanismos de tecnologia e informação mais forte que aqueles não são tão transparentes.

Esse resultado está em linha com os pressupostos da Teoria da Escolha Pública, uma vez que a transparência esteja associada à governança eletrônica, aquela se torna um dos mecanismos que limita o comportamento que maximiza o interesse particular do gestor (MUELLER, 1976; PEREIRA, 1997). Confirma com o que Cruz et al. (2012) traz em seu estudo, já que as ações de boa governança na gestão pública também estão relacionadas com práticas de disponibilização de informações de forma tempestiva e transparente aos diversos atores sociais.

Apesar de não existir estudos que mostram a relação entre a transparência, com base na $L A I$, ou até mesmo com a transparência fiscal da LRF, é importante mencionar os estudos 
de Braga et al. (2014), Angélico (2012) e Neves, Diniz e Martins (2015) que também investigaram as relações observadas na transparência com outras variáveis. Dessa forma, a contribuição deste estudo é para estudos futuros, já que buscou identificar possíveis novas relações entre a variável transparência com outras variáveis.

Percebe-se que existe influência positiva da transparência com a governança eletrônica dos estados brasileiros. É importante deixar claro que a governança eletrônica não é restrita a transparência, ela é mais abrangente, já que a governança eletrônica envolve "novos estilos de liderança, novas maneiras de acessar serviços públicos, novas maneiras de ouvir os cidadãos [...] e novas maneiras de organizar e fornecer informações" (OKOT-UMA, 2001, p. 5).

\section{CONCLUSÃO}

Este trabalho teve como objetivo analisar a influência dos indicadores socioeconômicos, contábeis e de transparência na governança eletrônica dos estados em 2011 a 2015. Para tanto, delineou-se este trabalho por meio de um estudo descritivo, com uma abordagem quantitativa, utilizando a técnica estatística de regressão com dados em painel. A amostra foi intencional e não probabilística compreendendo os 26 estados brasileiros.

Os resultados obtidos a partir das regressões calculadas sobre os dados obtidos, permitiu concluir que existe influência negativa entre as variáveis contábeis e os mecanismos de governança eletrônica dos estados brasileiros, além de uma relação positiva entre estes mecanismos de governança e a transparência dos estados, calculados a partir do EBT. No entanto, as variáveis socioeconômicas não foram passíveis de serem testadas, pois não se mostraram significantes, mas isso pode ter sido por causa da amostra obtida.

A partir destas constatações, foi possível analisar os resultados sob a ótica da Teoria da Escolha Pública, uma vez que constatou-se associação da governança eletrônica com aspectos contábeis e de transparência. No primeiro caso, quando os gestores utilizam mais recursos por meio de operações de crédito, tem uma dependência maior de recursos de terceiros e existem muitos gastos com pessoal, o índice de governança eletrônica se mostrou menor, o que corroborar com os autores Frant (1996), Downs (1999), Dias (2009) e Mota et al. (2017) uma vez que as decisões tomadas pelos gestores estão direcionadas em certo grau ao auto interesse, e as práticas de governança na gestão pública reduziriam essa defasagem na relação entre o Estado e sociedade. No segundo caso, a associação com a transparência se justifica pelo fato de esta se mostrar como um mecanismo que limita o comportamento oportunista do gestor (MUELLER, 1976; PEREIRA, 1997).

Portanto, os resultados sinalizam que os indicadores contábeis e a transparência são variáveis que contribuem para explicar a utilização de práticas de governança eletrônica nos estados brasileiros, o que corrobora com o estudo de Beuren, Moura, Kloeppel (2013). Deste modo, a contribuição dessa pesquisa é por trazer importantes evidências empíricas sobre os determinantes da governança eletrônica no caso dos governos estaduais brasileiros, trazendo explicações para a motivação desse comportamento. Essa pesquisa diferencia-se das demais pelo fato de que se observou os efeitos dos fatores contábeis e de transparência na governança eletrônica dos entes políticos estaduais, até então não observado no caso dos municípios brasileiros, além de abordar um período de cinco anos (2011 a 2015), o que permitiu verificar o comportamento desses gestores em diferentes momentos do tempo.

Assim, foi possível confirmar a relação esperada para as variáveis de transparência. No entanto, ao contrário do que se esperava, a relação encontrada para os indicadores 
contábeis foi negativa, levando a conclusão de que existe uma relação inversa entre os indicadores contábeis e a governança eletrônica dos estados, o que pode sugerir que não necessariamente entes políticos que se planejam de forma mais adequada são aqueles que têm uma estrutura de governança eletrônica melhor. Além disso, as variáveis socioeconômicas não se mostram significantes ao nível de $5 \%$, o que não permitiu concluir a respeito da relação esperada.

Outras contribuições dessa pesquisa são para instigar pesquisadores a abordar de forma mais aprofundada a relação entre variáveis socioeconômicas, contábeis e de transparência com a governança eletrônica no setor público, principalmente sob a ótica da Teoria da Escolha Pública, que pode sugerir explicações para algumas das relações entre essas variáveis. Essa discussão é fundamental, visto que a governança eletrônica não se refere apenas a disponibilização de serviços ou a uma administração pública mais eficiente, contribui para melhorar a qualidade dos gastos públicos à medida que aumenta a participação da sociedade no controle das ações governamentais (MELLO, 2009).

Como sugestões para pesquisas futuras sugere-se analisar por meio de estudos empíricos de forma mais aprofundada a realidade de governança eletrônica de órgão e/ou entidades públicas sob a ótica da Teoria da Escolha Pública para buscar possíveis explicações nas relações encontradas. Além disso, também indica-se outras pesquisas que façam um levantamento a respeito das relações entre as variáveis deste estudo e outras com esta teoria.

\section{REFERÊNCIAS}

ANGÉLICO, F. Lei de acesso à informação pública e seus possíveis desdobramentos à accountability democrática no Brasil. 2012. 133 f. Dissertação (Mestrado em Administração Pública e Governo) - Escola de Administração de Empresas de São Paulo, Fundação Getúlio Vargas, São Paulo, 2012.

ARAÚJO, W. F. G; LAIA, M. M. Governança eletrônica e gestão da informação em portais de governo: uma análise da reestruturação do Portal Minas. Anais do Encontro Nacional da Associação Nacional de Pós-Graduação e Pesquisa em Administração, Curitiba, PR, Brasil, v. 28, 2004.

AVELINO, B. C.; CUNHA, J. V. A.; COLAUTO, R. D.; LIMA, G. A. S. F.; PINHEIRO, L. E. T. Divulgação voluntária do ente público: um olhar sobre o estado de Minas Gerais. Enfoque: Reflexão Contábil, v. 33, n. 1, 2014.

BEUREN, I. M.; MOURA, G. D.; KLOEPPEL, N. R. Práticas de governança eletrônica e eficiência na utilização das receitas: uma análise nos estados brasileiros. Revista de Administração Pública-RAP, v. 47, n. 2, 2013.

BHUIYAN, Shahjahan H. Modernizing Bangladesh public administration through egovernance: Benefits and challenges. Government Information Quarterly, v. 28, n. 1, p. 5465, 2011. 
BRAGA, L. V.; ALVES, W. S.; COSTA FIGUEIREDO, R. M.; Santos, R. R. O papel do governo eletrônico no fortalecimento da governança do setor público. Revista do Serviço Público, v. 59, n. 1, p. 05-21, 2014.

BRASIL. Lei Complementar no 101, de 04/05/2000. Lei de Responsabilidade Fiscal. Estabelece normas de finanças públicas voltadas para a responsabilidade na gestão fiscal e dá outras providências.

BRASIL. Lei Complementar no 131, de 27/05/2005. Acrescenta dispositivos à Lei Complementar no 101, de 4 de maio de 2000, que estabelece normas de finanças públicas voltadas para a responsabilidade na gestão fiscal e dá outras providências, a fim de determinar a disponibilização, em tempo real, de informações pormenorizadas sobre a execução orçamentária e financeira da União, dos Estados, do Distrito Federal e dos Municípios.

BRASIL. Lei n. 12.527 de 18 de novembro de 2011. Lei de Acesso à informação. Regula o acesso a informações previsto no inciso XXXIII do art. 5o, no inciso II do § 30 do art. 37 e no § 20 do art. 216 da Constituição Federal; altera a Lei no 8.112, de 11 de dezembro de 1990; revoga a Lei no 11.111, de 5 de maio de 2005, e dispositivos da Lei no 8.159, de 8 de janeiro de 1991; e dá outras providências.

BUCHANAN, James M.; TULLOCK, Gordon. The Calculus of Consent: Logical Foundations of Constitutional Democracy (Ann Arbor Paperbacks). 1962.

BUCHANAN, James M. Politics without romance: A sketch of positive public choice theory and its normative implications. The theory of public choice II, v. 11, p. 22, 1984.

BUCHANAN, James M. Public choice: The origins and development of a research program. Champions of Freedom, v. 31, p. 13-32, 2003.

CAMPAGNONI, M.; CARVALHO, R. D.; LYRIO, M. V. L.; LUNKES, R. J.; ROSA, F. S. Transparência no poder legislativo municipal: uma análise dos portais eletrônicos das câmaras de vereadores das capitais brasileiras. Revista Gestão Organizacional, v. 9, n. 1, p. 21, 2016.

CAMPELLO, Carlos Alberto Gabrielli Barreto. Eficiência municipal: um estudo no Estado de São Paulo. 2003. Tese de Doutorado. Universidade de São Paulo.

COSTA, G. P. C. L.; FREIRE, F. S.; GARTNER, I. R.; CLEMENTE, A. As escolhas públicas orçamentárias federais no PPA 2008-2011: uma análise da perspectiva do modelo principalagente. Revista de Administração Pública, v. 47, n. 5, p. 1089-1116, 2013.

CRUZ, C. F. Transparência da gestão pública municipal: referenciais teóricos e a situação dos grandes municípios brasileiros. 2010. Dissertação de Mestrado, Universidade Federal do Rio de Janeiro, Rio de Janeiro, RJ, Brasil. 
CRUZ, C. F.; FERREIRA, A. S.; SILVA, L. M.; MACEDO, M. S. Transparência da gestão pública municipal: um estudo a partir dos portais eletrônicos dos maiores municípios brasileiros. Revista de Administração Pública, v. 46, n. 1, p. 153-176, 2012.

DIAS, Marco Antonio. James Buchanan e a "Política" na escolha pública. Revista Estratégica, v. 10, n. 1, 2013.

DINIZ, E. H.; BARBOSA, A. F.; JUNQUEIRA, A. R. B.; PRADO, O. O governo eletrônico no Brasil: perspectiva histórica a partir de um modelo estruturado de análise. Revista de Administração Pública-RAP, v. 43, n. 1, 2009.

DOWNS, A. Uma teoria econômica da democracia. São Paulo: Edusp, 1999.

EVANGELISTA, V. B.; NUNES, A. A. D. D. O.; RODRIGUES, E.; KRAUTER, E. O impacto das variáveis apontadas pela literatura no índice de governança eletrônica paulista. Anais do SEMEAD - Seminários em Administração, São Paulo, SP, Brasil, 18, 2015.

FIIRST, C.; COSTA, J. S.; BALDISSERA, J. F. DALL'ASTA, D. A influência de variáveis socioeconômicas e contábeis no índice de transparência eletrônica dos maiores municípios brasileiros, após a lei de acesso à informação. In: CONGRESSO DA ASSOCIAÇÃO NACIONAL DE PROGRAMAS DE PÓS-GRADUAÇÃO EM CONTABILIDADE, 10., 2017. Belo Horizonte, MG. 2017.

FIRJAN, Federação das Indústrias do Estado do Rio de Janeiro. Índice FIRJAN de Desenvolvimento Municipal (IFDM). 2016a. Recuperado em 22 fevereiro 2017, de https://goo.gl/T7mBnb

FIRJAN, Federação das Indústrias do Estado do Rio de Janeiro. Índice FIRJAN de Gestão Fiscal (IFGF). 2016b. Recuperado em 22 fevereiro 2017, de https://goo.gl/1oOoPA

FRANT, H. High-powered and low-powered incentives in the public sector. Journal of Public Administration Research and Theory, v. 6, n. 3, p. 365-381, 1996.

GUSMÃO, I. B.; JÚNIOR, L.; RAIFUR, L. Estrutura de capital e a competitividade das empresas brasileiras: um estudo na Bovespa no período de 1997-2007. XI SEMEAD-Seminários em Administração FEA/USP, v. 1, p. 1-1, 2008.

HUTHER, J.; SHAH, A. Applying a simple measure of good governance to the debate on fiscal decentralization. Social Science Research Network - SSRN. 1999.

JANOWSKI, T.; PARDO, T. A.; DAVIES, J. Government information networks: mapping electronic governance cases through public administration concepts. Government Information Quarterly, v. 29, p. 1-10, 2012.

JARDIM, J. M. (2004). A construção do e-gov no Brasil: configurações políticoinformacionais. Encontro Nacional da Ciência da Informação, v. 5, 2004. 
JARDIM, J. M. (2007). Governo eletrônico no Brasil: o portal rede governo. Arquivística. net, v. 3, n. 1, p. 28-37, 2007.

KAUFMANN, D.; LEAUTIER, F.; MASTRUZZI, M. Governance and the city: an empirical exploration into global determinants of urban performance. World Bank Policy Research Working Paper, 2005. Recuperado em 22 fevereiro 2017, de https://goo.gl/S8uvXi

LAMENHA, A. A. R.; LAMENHA, G. R. O controle de gestão nas organizações públicas municipais: uma análise das práticas de governança digital em alagoas. Olhares Plurais, v. 2, n. 11, p. 3-25, 2015.

LÓPEZ, A.; CORRADO, A. Indicadores de gestión para el monitoreo de las políticas de modernización en el sector público: revisión teórica y propuesta para su elaboración. Buenos Aires: Instituto Nacional de la Administración Pública (INAP). 2005.

LOURENÇON, C. O orçamento municipal como elo de ligação entre o planejamento operacional e as finanças. Dissertação de Mestrado, Universidade Federal de Santa Catarina, Florianópolis, SC, Brasil, 2001.

MACEDO, J. J.; CORBARI, E. C. Efeitos da lei de responsabilidade fiscal no endividamento dos municípios brasileiros: uma análise de dados em painéis. Revista Contabilidade \& FinançasUSP, v. 20, n. 51, 2009.

MELLO, G. R. Estudo das práticas de governança eletrônica: instrumento de controladoria para a tomada de decisões na gestão dos estados brasileiros. Tese de Doutorado, Faculdade de Economia, Administração e Contabilidade, Universidade de São Paulo, São Paulo, SP, Brasil, 2009.

MOURA, G. D.; DALLABONA, L. F.; FANK, O. L.; ALMEIDA-SANTOS, P. S.; VARELA, P. S. Análise das práticas de governança eletrônica de municípios do Estado de Santa Catarina. Ágora: revista de divulgação científica, v. 20, n. 2, p. 84-106, 2015.

MUELLER, Dennis C. Public choice: A survey. Journal of Economic Literature, v. 14, n. 2, p. 395-433, 1976.

NEVES, A. C. D.; DINIZ, J. A.; MARTINS, V. G. Determinantes socioeconômicos da transparência fiscal. Anais do Congresso USP de Controladoria e Contabilidade. São Paulo, SP, Brasil, 14, 2015.

PEREIRA, Paulo Trigo. A teoria da escolha pública (public choice): uma abordagem neoliberal?. Análise Social, v. 32, n. 141, p. 419-442, 1997.

POTNIS, D. D. Measuring e-Governance as an innovation in the public sector. Government Information Quarterly, v. 27, n. 1, p. 41-48, 2010.

OKOT-UMA, R. Electronic governance: re-inventing good governance. Londres:

Commonwealth Secretariat London, 2001. 
RAUPP, Fabiano Maury; PINHO, José Antonio Gomes. Construindo a accountability em portais eletrônicos de câmaras municipais: um estudo de caso em Santa Catarina. Cadernos Ebape. Br, v. 9, n. 1, p. 117-139, 2011.

REZENDE, D. A.; FREY, K. Administração estratégica e governança eletrônica na gestão urbana. Revista Eletrônica de Gestão de Negócios, v. 1, n. 1, p. 51-59, 2005.

RIBEIRO, C. P. P.; ABRANTES, L. A.; FERREIRA, M. A. M.; GOMES, A. P. A influência da Lei de Responsabilidade Fiscal nos indicadores socioeconômicos dos municípios mineiros. Anais do Encontro Nacional da Associação Nacional de Pós-Graduação e Pesquisa em Administração, Rio de Janeiro, 36, 2012.

RIBEIRO, C. P. P.; ZUCCOLOTTO, R. A face oculta do Leviatã: transparência fiscal nos municípios brasileiros e suas determinantes socioeconômicas e fiscais. Enfoque: Reflexão Contábil, v. 33, n. 1, p. 37-52, 2014.

ROTHBERG, D. Por uma agenda de pesquisa em democracia eletrônica. Opinião Pública, v. 14, n. 1, p. 149-172, 2008.

RUCKERT, I. N.; BORSATTO, M. L.; RABELO, M. As finanças municipais e os gastos sociais no Rio Grande do Sul, 1995-99. Secretaria da Coordenação e Planejamento, Fundação de Economia e Estatística Siegfried Emanuel Heuser, 2002.

SANTOS, S. R. T.; ALVES, T. W. O impacto da Lei de Responsabilidade Fiscal no desempenho financeiro e na execução orçamentária dos municípios no Rio Grande do Sul de 1997 a 2004. Revista de Administração Pública, v. 45, n. 1, p. 181-208, 2011.

SOARES JÚNIOR, J. S.; SANTOS, E. M. Governança eletrônica: uma perspectiva sociotécnica das organizações públicas a partir da padronização e interoperabilidade. Anais do Encontro Nacional da Associação Nacional de Pós-Graduação e Pesquisa em Administração, v. 31, p. 1-16, 2007.

SOUZA, F. J. V. D.; SILVA, M. C. D.; ARAÚJO, A. O.; SILVA, J. D. G. D. Uma análise sobre a evidenciação das contas públicas das Capitais brasileiras. Enfoque: Reflexão Contábil, v. 29, n. 1, p. 79-92, 2010. 